\title{
Enzymatic and Immunologic Quantitation of Erythrocyte Superoxide Dismutase in Adults and in Neonates of Different Gestational Ages
}

\author{
LOUISE A. SAIK ${ }^{(39)}$, HUI-LUNG HSIEH, WILLIAM H. BARICOS, AND EMMANUEL SHAPIRA ${ }^{(41))}$ \\ The Hayward Genetics Center, Departments of Biochemistry, Pediatrics, and Pathology, Tulane University School of \\ Medicine, New Orleans, Louisiana, USA
}

\begin{abstract}
Summary
Human erythrocyte superoxide dismutase (SOD) was purified and specific antiserum was raised in rabbits. Enzyme preparations from adults and from newborns were shown to be indistinguishable in their immunologic and electrophoretic properties. Erythrocyte SOD was quantitated in blood specimens from adults and in cord blood specimens from neonates of different gestational ages, using both an immunologic and an activity assay. The mean values of SOD concentration and SOD activity for adults and for newborns of average size for gestational age (AGA) showed no significant difference. Adult red cells contained $28.0 \pm 8.3$ SOD units $/ \mathrm{mg}$ hemoglobin (Hgb) whereas AGA neonatal red cells had $28.5 \pm 8.3$ SOD units/mg Hgb. Immunologic quantitation by single radial immunodiffusion revealed $0.69 \pm 0.07 \mu \mathrm{g} \mathrm{SOD} / \mathrm{mg} \mathrm{Hgb}$ in adults and $0.70 \pm 0.14 \mu \mathrm{g} \mathrm{SOD} / \mathrm{mg} \mathrm{Hgb}$ in the AGA neonates; however, the SOD concentrations from both small for gestational age (SGA) and large for gestational age (LGA) neonates were significantly lower than those of the AGA neonates and the adults (SGA: $0.57 \pm 0.24 \mu \mathrm{g} \mathrm{SOD} / \mathrm{mg} \mathrm{Hgb}, P<0.05 ;$ LGA: $0.59 \pm 0.16 \mu \mathrm{g}$ $\mathrm{SOD} / \mathrm{mg} \mathrm{Hgb}, P<0.05$ ).
\end{abstract}

\section{Speculation}

The relatively small quantitative differences in cytosolic superoxide dismutase are unlikely to account for an increased susceptibility to oxygen therapy. The possibility of a decrease in the mitochondrial superoxide dismutase isoenzyme has yet to be studied.

Although oxygen is vital to the survival of aerobic cells, an excess of oxygen has been associated with certain disease states such as bronchopulmonary dysplasia $(2,5,24,25)$, retrolental fibroplasia (14), and drug-induced hemolytic anemia in neonates $(11,12,26)$. Superoxide radical $\left(\mathrm{O}_{2} \cdot\right)$ is thought to mediate this oxygen toxicity, either directly or indirectly via its two reactive products, hydroxyl radical $(\mathrm{OH} \cdot)$ and singlet oxygen $\left({ }^{1} \mathrm{O}_{2}\right)(7,8$, $9,34)$. On the molecular level, superoxide has been implicated in the initiation of lipid peroxidation, the oxidation of thiol groups, and the oxidation of purines and pyrimidines $(4,7,8,9,17)$. The two superoxide dismutase (SOD) isoenzymes (SOD 1 and SOD 2) are metalloenzymes that catalyze the reaction: $\mathrm{O}_{2} \cdot{ }^{-}+\mathrm{O}_{2} \cdot{ }^{-}+$ $2 \mathrm{H}^{+} \rightarrow \mathrm{H}_{2} \mathrm{O}_{2}+\mathrm{O}_{2}$. These isoenzymes are thought to comprise the major protective mechanism against the deleterious effects of oxygen $(8,9,10,13,21,27)$. SOD 1 is a cyanide sensitive, copperzinc enzyme found primarily in the cytoplasm of cells, whereas SOD 2 is a cyanide resistant, manganese-containing protein found in the mitochondrial matrix $(4,8,9,10,13,17,21,37)$. Erythrocytes contain only the SOD 1 isoenzyme (8).

Because neonates are susceptible to oxygen-related diseases and SOD appears to be the major protection against oxygen toxicity, the SOD activity in neonate erythrocytes has been previously studied; however, contradictory data have been reported. Ueda et al. (34) and Yoshioka et al. (38) found insignificant variations in red cell SOD activity of newborn infants and adults. In contrast, Autor et al. (1) showed significantly lower red cell SOD activity in newborns when compared to adults. No significant differences in red cell SOD activity of premature infants, infants with respiratory distress syndrome (RDS), and normal infants were found by some investigators (1); however, Bonta et al. (3) demonstrated an inverse relationship between red cell SOD activity and gestational age and showed lower SOD levels in RDS newborns than in their normal counterparts.

In all of these investigations an activity assay was used to measure SOD levels. The various activity assays used are all indirect and are thus subject to high error, especially in the determination of SOD in tissue homogenates $(1,3,4,8-10,13,17$, $20,21,34,37,38)$. In order to overcome the drawbacks inherent in the use of these activity assays, we developed a quantitative immunoassay for SOD 1 protein that also avoids the limitations of activity loss or inhibition of the enzyme during hemolysate preparation and storage. Red cell SOD levels in adults and newborns were compared using both an immunologic method and an activity assay. The SOD levels in the newborns were correlated to their gestational age.

\section{MATERIALS AND METHODS}

Materials. Agarose, $o$-dianisidine $\mathrm{HCl}$, Coomassie Brilliant Blue $\mathrm{R}$, nitroblue tetrazolium (NBT), xanthine oxidase (Lot \#1875, 24 units $/ \mathrm{ml}$ ), and cyanide reagents for the colorimetric determination of hemoglobin were obtained from Sigma Chemical Company. Diethylaminoethyl (DEAE)-cellulose was purchased from Bio Rad Laboratories and Sephadex G-100 was from Pharmacia Fine Chemicals. Ampholines, pH 3-10, and Agarose-EF were from LKB Instruments, Inc. Agar (Noble) was obtained from Difco Laboratories and agarose gel plates for immunoelectrophoresis were purchased from Bioware Products. Nonidet P-40 (NP-40) was obtained from Bethesda Research Laboratories. All other reagents were either reagent grade or the best grade available.

Blood specimens. Blood $(2-3 \mathrm{ml})$ was obtained, after signed informed consent, by venipuncture from healthy adults (ages 25 65 ) and from umbilical cords of newborn infants. Sodium heparin was used as an anticoagulant. The birthweights of the newborns were recorded and their gestational ages determined according to Dubowitz et al. (16). The blood was centrifuged at $700 \times g$ for 20 min and the plasma and buffy coat removed by aspiration. After the red cells were washed twice with two volumes of phosphate buffered saline (PBS), pH 7.0, the erythrocytes were lysed and the membranes solubilized by the addition of an equal volume (1:1) of $0.5 \% \mathrm{NP}-40$ in water. The hemoglobin concentration of the hemolysates was determined using the hemoglobin-cyanide procedure (35).

Preparation of hemoglobin-free hemolysate $(H F H)$. Hgb was removed using a modified Tsuchihashi procedure (33). Ethanol and chloroform $(0.32: 0.40, \mathrm{v} / \mathrm{v})$, precooled to $-15^{\circ} \mathrm{C}$, were added to the red cell lysate, and the mixture was stirred with an overhead 
stirrer at $4^{\circ} \mathrm{C}$ for $30 \mathrm{~min}$. The viscous material was centrifuged to remove the denatured $\mathrm{Hgb}$, and the upper ethanol phase containing the SOD was dialyzed against $0.0025 \mathrm{M}$ potassium phosphate buffer, $\mathrm{pH}$ 7.4. Protein concentration was determined according to Lowry et al. (18).

Immunization procedure. Two New Zealand white rabbits were immunized, each with $2 \mathrm{mg}$ purified human SOD 1 in complete Freund's adjuvant (GIBCO) at multiple intradermal sites as previously described (29). Blood was collected weekly beginning 10 days after immunization from the marginal ear vein. The serum was separated, pooled, and stored at $-20^{\circ} \mathrm{C}$ until used. The $\operatorname{IgG}$ fraction was obtained by $40 \%$ ammonium sulfate precipitation.

Enzyme activity assay. SOD 1 activity in red cell lysates was determined using the xanthine-xanthine oxidase-NBT assay of Yoshioka et al. (38), as follows: The reaction mixture $(2 \mathrm{ml})$ contained $6.3 \times 10^{-5} \mathrm{M}$ EDTA, $6.3 \times 10^{-5} \mathrm{M}$ xanthine, $1.6 \times 10^{-5}$ $\mathrm{M}$ NBT in $0.05 \mathrm{M}$ carbonate buffer, $\mathrm{pH}$ 10.2. Xanthine oxidase was added at a concentration such that the absorbance at $560 \mathrm{~nm}$ increased 0.1 in a 10 -min time interval.

The extent of inhibition of the reaction by hemolysate dilutions of known $\mathrm{Hgb}$ concentrations was plotted on a semilogarithmic scale in order to determine the amount required for $50 \%$ inhibition. The amount of SOD activity resulting in 50\% inhibition was defined arbitrarily as one unit of SOD activity (16). No detectable enzymatic activity was found in the presence of cyanide with the assay conditions as previously described (8).

The enzymatic activity in the column chromatography fractions was assayed using the $o$-dianisidine riboflavin assay according to Misra and Fridovich (22). The residual enzymatic SOD activity of the immunoprecipitin bands and isoelectric focusing gels was determined using the same assay as described by Misra and Fridovich (23).

Isoelectric focusing. Analytical isoelectric focusing was performed on $0.8 \%$ agarose slab gels containing $2 \%$ ampholines $(\mathrm{pH}$ range of 3-10) using an LKB Multiphor 2117 system, according to the manufacturer's instructions. Preparative isoelectric focusing on vertical polyacrylamide gel slabs was performed as previously described (31).

Immunological techniques. Erythrocyte SOD 1 was quantitated by single radial immunodiffusion according to Mancini et al. (19). The plates (disposable petri dishes of 9-cm diameter) contained $14 \mathrm{ml}$ of $1 \%$ agarose in PBS, $\mathrm{pH} 7.0$, with $0.58 \mathrm{mg} / \mathrm{ml}$ anti-SOD IgG fraction. Wells of identical size were punched using an appropriate template, and $7 \mu \mathrm{l}$ of hemolysate (Hgb range, $50-100$ $\mathrm{mg} / \mathrm{ml}$ ) were added. After incubation at $4^{\circ} \mathrm{C}$ for $72 \mathrm{~h}$ in a humid chamber, the ring diameters were measured. On each plate four concentrations of purified SOD 1 (range of $10-80 \mu \mathrm{g}$ SOD $/ \mathrm{ml}$ ) were applied, and a linear standard curve was obtained from their ring diameters. All determinations were done in duplicate. Double gel diffusion and immunoelectrophoresis were performed as previously described (32). Immunodiffusion after isoelectric focusing (immunoisoelectric focusing) was obtained by cutting a $1-\mathrm{mm}$ trough in the agarose slab gels parallel to the electrofocused enzyme preparation. The trough was filled with anti-SOD antiserum (diluted 1:1 with $0.1 \mathrm{M}$ phosphate buffer, $\mathrm{pH} 7.5$ ), and after overnight diffusion at room temperature the immunoprecipitin arcs were revealed.

\section{RESULTS}

Purification of SOD 1 and preparation of monospecific antiserum. The hemoglobin-free hemolysate $(\mathrm{HFH})$ fraction was prepared from a pool of five individual packed red cell preparations obtained from a local blood bank. This HFH preparation $(3.2 \mathrm{~g})$ was dialyzed exhaustively against $0.0025 \mathrm{M}$ potassium phosphate buffer, pH 7.4, and applied to a DEAE-cellulose column $(2.5 \times$ $105 \mathrm{~cm}$ ), equilibrated with the same buffer. The various protein fractions were eluted with a linear molarity gradient $(0.0025-0.2$ $\mathrm{M}$ phosphate buffer, $\mathrm{pH}$ 7.4). The third peak eluted from the column (at $0.02 \mathrm{M}$ ) was the only peak with SOD activity. This peak was concentrated by Amicon ultrafiltration using a UM-10 membrane and applied to a Sephadex G-100 column $(3.5 \times 105$ $\mathrm{cm}$, equilibrated and eluted with $0.01 \mathrm{M}$ phosphate buffer, $\mathrm{pH}$ $7.5)$. The SOD activity was eluted in the second protein peak. The yield after these steps was approximately $40 \%$. After concentration, $5 \mathrm{mg}$ of this SOD preparation was applied for preparative polyacrylamide isoelectric focusing in the $\mathrm{pH}$ range of 4-6.

The band with SOD activity was carefully excised and homogenized in $0.01 \mathrm{M}$ phosphate buffer, $\mathrm{pH} 7.5$. After centrifugation, the supernatant was dialyzed against the same buffer, and protein concentration was determined. This highly purified preparation of SOD 1 obtained by the preparative isoelectric focusing was used for immunization. The monospecificity of the antiserum obtained was demonstrated by immunoelectrophoresis and immunoisoelectric focusing (Fig. 1).

Comparison of adult and newborn SOD 1 preparations. The antigenic properties and electrophoretic mobility of $\mathrm{HFH}$ preparations from five adult controls and five newborn cord blood specimens were compared. On double gel diffusion, the adult and newborn hemolysates gave a single precipitin line of identity that retained residual enzymatic activity. Immunoelectrophoresis (Fig. 1A) revealed a single precipitin arc with identical electrophoretic mobility for both the adult and newborn hemolysates. When compared by isoelectric focusing on agarose slabs, one band with SOD activity identical for both preparations was revealed (Fig. 1B). Immunodiffusion after the isoelectric focusing (Fig. IC) revealed single, identical precipitin arcs.

$S O D$ activity and concentration in adult and newborn hemolysates. As the adult and newborn SOD 1 preparations were shown to be immunologically identical, their concentrations could be compared using a quantitative immunologic procedure, single radial immunodiffusion. A linear standard curve was obtained in the concentration range of $10-80 \mu \mathrm{g} \mathrm{SOD} / \mathrm{ml}$. The results are shown in Figure 2. The immunoprecipitin rings revealed residual enzymatic SOD activity (Fig. 2 insert). The SOD concentrations were determined in 20 adult blood specimens and in 46 cord blood specimens from newborns of average size for gestational age (AGA). The results are shown in Figure 3. In adults a concentration of $0.69 \pm 0.07 \mu \mathrm{g} \mathrm{SOD} / \mathrm{mg} \mathrm{Hgb}$ was found, and in newborns a concentration of $0.70 \pm 0.14 \mu \mathrm{g} \mathrm{SOD} / \mathrm{mg} \mathrm{Hgb}$ was shown. The SOD activity of the various hemolysate preparations was determined and found to be $28.0 \pm 8.3$ units $/ \mathrm{mg} \mathrm{Hgb}$ in adults and $28.5 \pm 8.3 \mathrm{units} / \mathrm{mg} \mathrm{Hgb}$ in neonates of AGA. For the various SOD preparations examined a specific activity of $40.8 \pm 9.5$ units/ $\mu \mathrm{g}$ SOD was determined. As the ratio of SOD activity to SOD concentration (using the immunologic method) in the various specimens was relatively constant for both newborn and adult hemolysate preparations, the immunologic quantitation was chosen for further comparison of SOD in newborns of different gestational ages.

Comparison of SOD concentration in newborns of different gestational ages. Cord blood specimens from neonates of different gestational ages were compared by their SOD 1 concentrations. The results are shown in Figure 4. In small for gestational age neonates (SGA), the SOD concentration was $0.57 \pm 0.24 \mu \mathrm{g}$ SOD/ $\mathrm{mg} \mathrm{Hgb}$. This concentration was significantly lower $(t=2.05 ; P$ $<0.05)$ than the AGA neonate SOD concentration $(0.69 \pm 0.15$ $\mu \mathrm{g} \mathrm{SOD} / \mathrm{mg} \mathrm{Hgb}$ ). In large for gestational age neonates (LGA) the SOD concentration was $0.59 \pm 0.16 \mu \mathrm{g} \mathrm{SOD} / \mathrm{mg} \mathrm{Hgb}$, a value very similar to that of the SGA neonates and significantly lower than that of the AGA neonates $(t=2.24 ; P<0.05)$. The hemolysates of both SGA and LGA neonates had significantly lower SOD concentrations than the adult hemolysates $(t=2.09 ; P<$ 0.05 for SGA and $t=2.38 ; P<0.05$ for LGA). The correlation between birthweight and SOD concentration was examined and not found to be statistically significant. The range of SOD concentration in the neonate group $(0.27-1.21 \mu \mathrm{g} / \mathrm{mg} \mathrm{Hgb})$ was much broader than the range of SOD concentration in adult controls $(0.58-0.82 \mu \mathrm{g} / \mathrm{mg} \mathrm{Hgb})$.

\section{DISCUSSION}

Although activity assays for quantitation of SOD are widely used, they have many drawbacks. Because the substrate superox- 


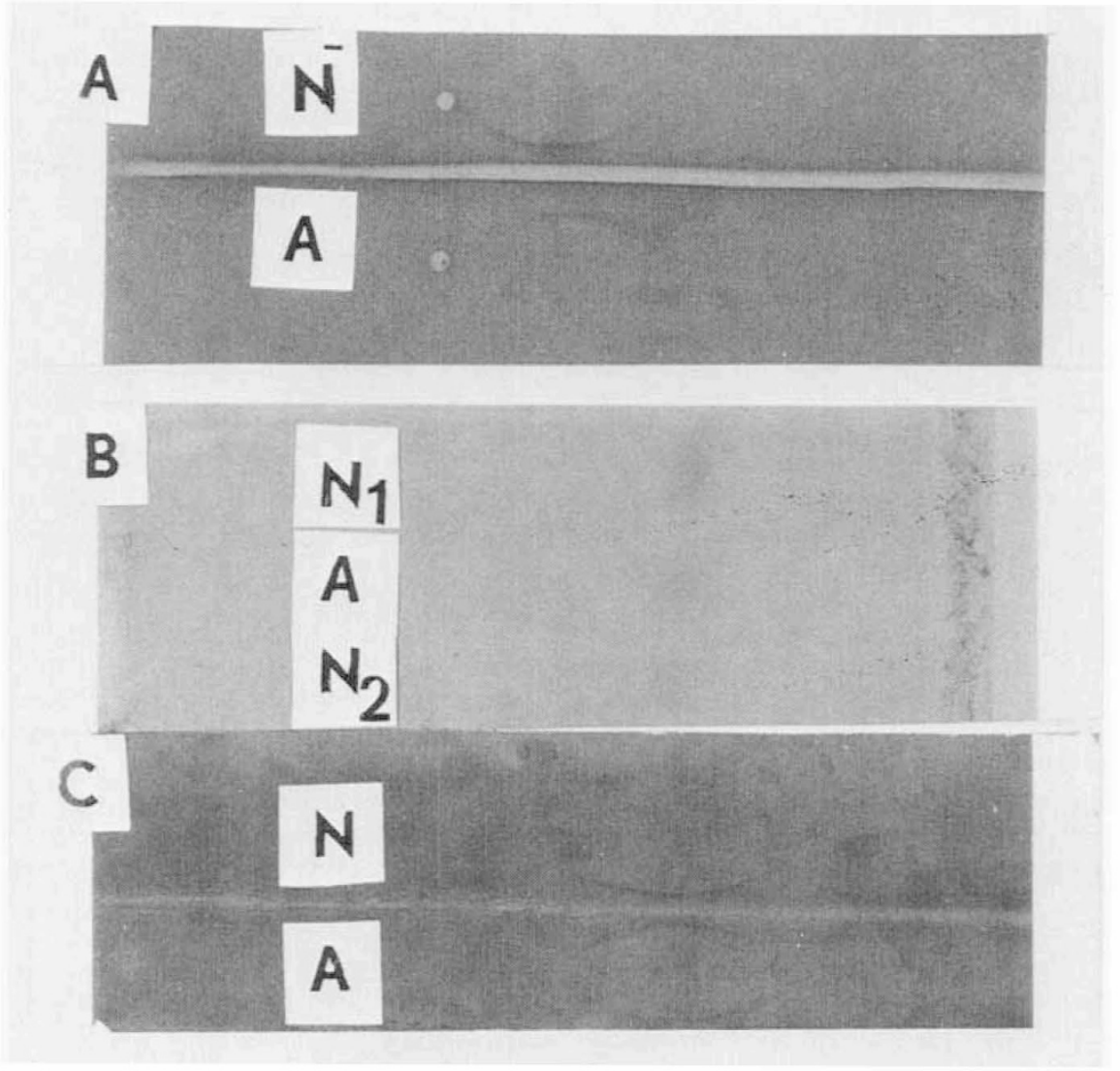

Fig. 1. Comparison of hemoglobin-free hemolysate preparations from adults $(A)$ and newborns $(N)$. Upper section A: immunoelectrophoresis with anti-superoxide dismutase (SOD) 1 antiserum. Middle section B: agarose slab isoelectric focusing for residual SOD activity. Lower section C: immunodiffusion after isoelectric focusing (immunoisoelectric focusing) with anti-SOD 1 antiserum.

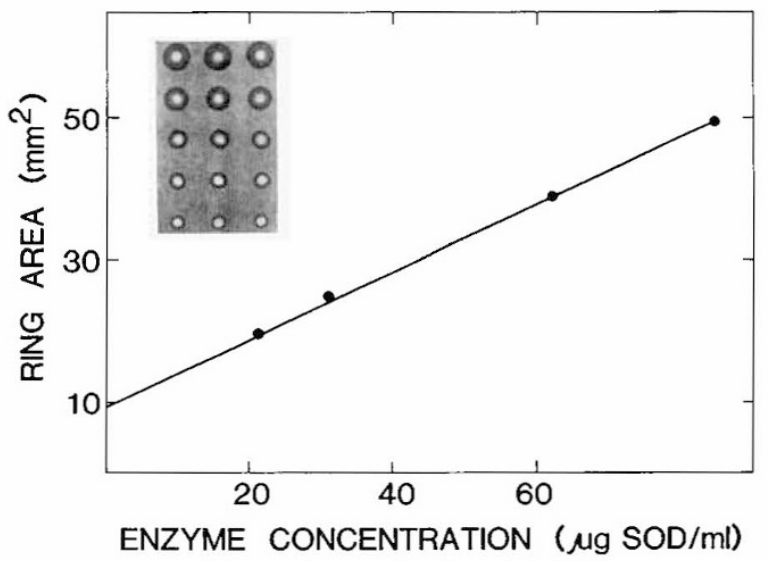

Fig. 2. Single radial immunodiffusion standard curve. Insert shows the residual enzymatic activity of the precipitin rings.

ide is relatively unstable, most enzymatic assays for SOD are indirect and involve two components, a superoxide generator and a superoxide detector (20). The addition of the enzyme to this system results in a competition between SOD and the detector for the available superoxide, expressed as a decrease of the detection phenomenon. All thse assays are time consuming and are unsuitable for quantitation of SOD in large numbers of samples. In addition, tissue homogenates frequently contain compounds that react nonspecifically with these detectors, decreasing their reliability in a quantitative assay (20). These drawbacks in SOD quantitation using an indirect activity assay might account, at least partially, for the contradictory data reported of SOD concentration in newborns. Some investigators (1) documented lower red cell SOD activity in newborns, whereas other investigators (34, 38) found insignificant variations.

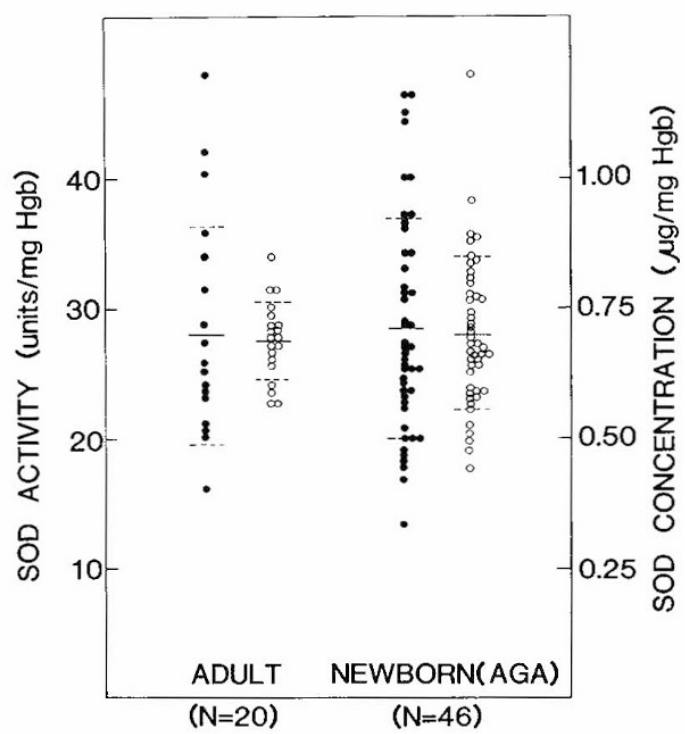

Fig. 3. Comparison of superoxide dismutase (SOD) enzymatic activity (solid symbols) and SOD concentration (open symbols) from hemolysates of adults and newborns of average size for gestational age (AGA). The number of individuals in each group is shown in parentheses.

A quantitative immunoassay, on the other hand, is highly specific, relatively easy, convenient, and not susceptible to interfering compounds as in an activity assay. Such an assay is especially suitable for the determination of SOD concentrations in a large number of biologic samples. In the present study a monospecific antiserum to SOD 1 was generated in rabbits. The monospecificity of this antiserum was documented by the observation that crude enzyme preparations revealed only one precipitin arc 


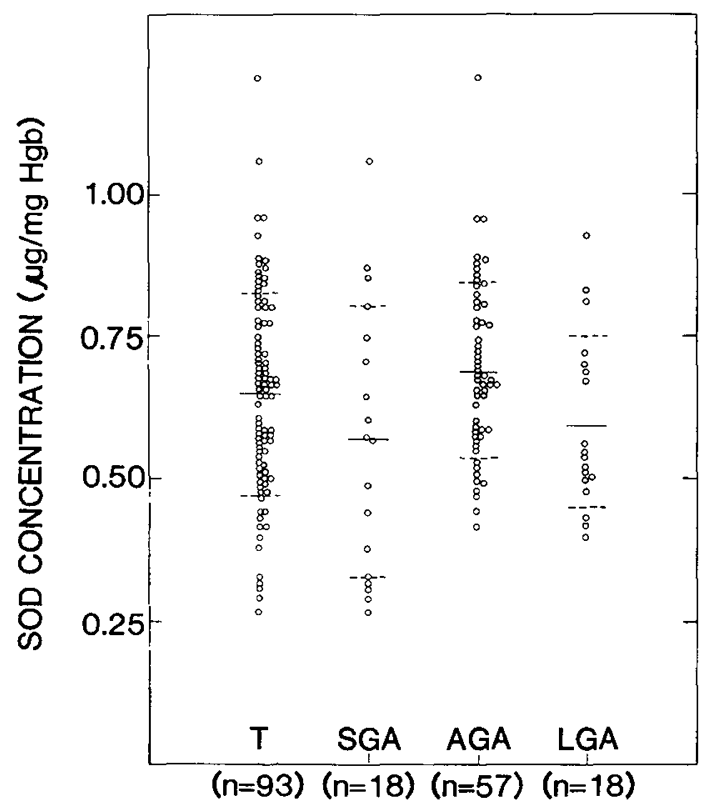

Fig. 4. Cord blood hemolysate superoxide dismutase concentrations from neonates of different gestational age: small for gestational age ( $S G A)$, average for gestational age $(A G A)$, large for gestational age $(L G A)$, and the total newborn group $(T)$. The number of determinations in each group is shown in parentheses.

by both immunoelectrophoresis and immunoisoelectric focusing (Fig. 1). The residual enzymatic activity of the immunoprecipitate indicated its specificity toward SOD (Fig. 2 insert). Using this specific antiserum, a simple quantitative immunoassay was developed, suitable «ur assaying a large number of hemolysate samples. The values obtained by this assay correlate to those obtained by the enzymatic activity assay (Fig. 3), but the immunologic quantitation is technically much simpler and faster as well as free of the methodologic drawbacks of the enzymatic quantitation.

The possibility of an embryonal form of SOD 1 in newborns is highly unlikely as the newborn SOD preparations were indistinguishable by their net electrical charge (isoelectric focusing) and immunologic reactivity wher, compared to the adult enzyme (Fig. 1). The same quantitative immunoassay also is suitable for quantitation of SOD in hemolysates from newborns. When the SOD concentrations in adult and newborn specimens were determined by both the quantitative immunoassay and the activity assay, no significant differences were revealed (Fig. 3); however, when the concentration of SOD of newborns either small or large for gestational age was determined, a lower concentration, statistically significant, was revealed when compared to either newborns of average size for gestational age or adults (Fig. 4). A different proportion of newborns of appropriate and inappropriate size for gestational age within a study group might account, at least in part, for the contradictory values previously reported $(1,34,38)$.

An interesting observation in the present study was the phenomenon that the relative decrease in SOD concentration was seen in both SGA and LGA newborn groups. Preliminary data in our laboratory recently documented the same phenomenon for red cell anhydrase B. The relatively lower concentration in SGA newborns for both SOD and carbonic anhydrase might reflect a maturation phenomenon. The observation that such decreased enzymatic concentration also was shown in the LGA newborns might suggest some similarity in the pathophysiology of the LGA and SGA groups.

A decreased enzyme concentration in newborns when compared to adults has been documented for several enzymes. In some, like carbonic anhydrase B, newborns showed $5-15 \%$ of adult values whereas in small, premature infants the enzyme concentration was only $2-3 \%(15,28,30,36)$. Although a statistically significant decrease in SOD concentration was shown in the present study for LGA and SGA neonates (when compared to those of AGA newborns and adults), these relatively small quantitative differences are unlikely to account for the increased susceptibility of LGA and SGA newborns to oxygen therapy sequelae. The possibility of a localized deficiency of SOD 1 in lung tissue and, even more so, the possibility of a generalized or a tissue-specific deficiency of the mitochondrial SOD 2 mangano-isoenzyme has yet to be studied.

\section{REFERENCES AND NOTES}

1. Autor, A. P., Frank, L., and Roberts, R. J.: Developmental characteristics of pulmonary superoxide dismutase: relationship to idiopathic respiratory distress syndrome. Pediatr. Res., 10: 154 (1976)

2. Autor, A. P. and Roberts, R. J.: Superoxide dismutase activity and isoenzymes in the human fetal and adult lung. Fed. Proc., 33: 1505 (1974).

3. Bonta, B. W., Gawron, E. R., and Warshaw, J. B.: Neonatal red cell superoxide dismutase enzyme levels: possible role as a cellular defense mechanism against pulmonary oxygen toxicity. Pediatr. Res., 11: 754 (1977).

4. Chvapil, M. and Peng, Y. M.: Oxygen and hung fibrosis. Arch. Environ. Health, 30: 528 (1975)

5. Crapo. J. D. and Tierney, D. F.: Superoxide dismutase and pulmonary oxygen toxicity. Am. J. Physiol., 226: 1401 (1974).

6. Dubowitz, L. M., Dubowitz, V., and Goldberg, C.: Clinical assessment of gestational age in the newborn infant. J. Pediat., 77: 1 (1970)

7. Feeney, L. and Berman, E. R.: Oxygen toxicity: membrane damage by free radicals. Invest. Opthal., 15: 789 (1976)

8. Fridovich. I.: Superoxide dismutases. Adv. Enzymol., 41: 35 (1974).

9. Fridovich, I.: Superoxide dismutase. In: O. Hayaishi: Molecular Mechanism of Oxygen Activation. p 453 (Academic Press, Inc., New York, New York. 1974).

10. Fridovich, I.: The biology of oxygen radicals. Science, 201: 875 (1978).

11. Goldberg, B. and Stern, A.: Superoxide anion as a mediator of drug-induced oxidative hemolysis. J. Biol. Chem., 251: 6468 (1976).

12. Goldberg, B. and Stern, A.: The role of the superoxide anion as a toxic species in the erythrocyte. Arch. Biochem. Biophys., I78: 218 (1977).

13. Gregory, E. M. and Fridovich, I.: Oxygen toxicity and the superoxide dismutase J. Bacteriol., 114: 1193 (1973).

14. James, S. and Lanman, J. T.: History of oxygen therapy and retrolental fibroplasia. Pediatrics, 57: 591 (1976).

15. Kleinman, L. I., Petering, H. G.. and Sutherland, J. M.: Blood carbonic anhydrase activity and zinc concentration in infants with respiratory-distress syndrome. New Engl. J. Med., 277: 1157 (1967).

16. Kobayashi, Y., Ishigame, K., Ishigame, Y., and Usui, T.: Superoxide dismutase activity of human blood cells. In: O. Hayaishi and K. Asada: Biochemical and Medical Aspects of Active Oxygen. p 261 (University Park Press, London, 1977).

17. Lavelle, F., Micheison, A. M., and Dimitrijevic, L.: Biological protection by superoxide dismutase. Biochem. Biophys. Res. Comm., 55: 350 (1973).

18. Lowry, O. H., Rosebrough, N. J., Farr, A. L., and Randall, R. J.: Protein measurement with the Folin phenol reagent. J. Biol. Chem., 193: 265 (1951).

19. Mancini, G., Carbonara, A. O., and Heremans, J. F.: Immunochemical quantitation of antigens by single radial immunodiffusion. Immunochem., 2: 235 (1965).

20. McCord, J. M., Crapo, J. D., and Fridovich, I.: Superoxide dismutase assays: a review of methodology. In: A. M. Michelson, J. M. McCord and I. Fridovich: Superoxide and Superoxide Dismutases. p II (Academic Press, Inc.. New York, New York, 1977).

21. McCord, J. M., Keele, B., and Fridovich, I.: An enzyme-based theory of obligate anaerobiosis: the physiological function of superoxide dismutase. Proc. Natl Acad. Sci. USA, 68: 1024 (1971).

22. Misra, H. P. and Fridovich, I.: Superoxide dismutase: a photochemical augmentation assay. Arch. Biochem. Biophys., 181: 308 (1977).

23. Misra, H. P. and Fridovich, I.: Superoxide dismutase and peroxidase: a positive activity stain applicable to polyacrylamide gel electropherograms. Arch. Biochem. Biophys., 183: 511 (1977)

24. Northway, Jr., W. H., Rosan, R. C., and Porter, D. Y.: Pulmonary disease following respirator therapy of hyaline-membrane disease. New Engl. J. Med. 276: 357 (1967)

25. Roberts, R., Frank, L., and Autor, A.: Superoxide dismutase: an enzyme of maturation-relationship of IRDS. Pediatr. Res. (Abstract), 9: 279 (1975).

26. Rotilio, G., Rego, A., Bracci, R., Bagnoli, F. Sargentini, I., and Brunori, M. Determination of red blood cell superoxide dismutase and glutathione peroxidase in newborns in relation to neonatal hemolysis. Clin. Chim. Acta., 81: 131 (1977).

27. Saltzman, H. A. and Fridovich, I.: Oxygen toxicity. Introduction to a protective enzyme: superoxide dismutase. Circulation, 48: 921 (1973)

28. Sell, J. E. and Petering, H. G.: Carbonic anhydrases from human neonatal erythrocytes. J. Lab. Clin. Med., 84: 369 (1974)

29. Shapira, E. and Arnon, R.: Effect of immunization course on inhibitory capacity of anti-enzyme antibodies. Immunochem., 5: 501 (1968).

30. Shapira, E., Ben-Yoseph, Y., Schenker, J., and Russell, A.: Cord blood carbonic anhydrase B concentration and birthweight. Isr. J. Med. Sci., 8: 950 (1972)

31. Shapira, E., David, A., DeGregorio, R., and Nadler, H. L.: Separation of $\beta$ galactosidases and $\beta$-glucosidases from human liver. Enzyme, 21: 332 (1976).

32. Shapira, E., DeGregorio, R., and Nadler, H.: Immunologic studies of arylsulfatase 
A in normal and metachromatic leukodystrophy liver. Pediatr. Res., 12: 199 (1978).

33. Tsuchihashi. M.: Über die reinigung der fumarase. Biochem. Z., 140: 161 (1923).

34. Ueda, K. and Ogata, M.: Levels of erythrocyte superoxide dismutase in Japanese people. Acta Med. Okayama, 32: 393 (1978)

35. Van Kampen, E. J. and Zijlstra, W. G.: Standardization of hemoglobinometry. II, The hemiglobincyanide method. Clin. Chim. Acta., 6: 538 (1961).

36. Wehinger, H.: Zur Natur und ontogenetischen Entwicklung von Carbonanhydrase-isoenzymen in menschlichen Erythrozyton. Blut, 27: 172 (1973).

37. Weisiger. R. A. and Fridovich, I.: Mitochondrial superoxide dismutase. Site of synthesis and intramitochondrial localization. J. Biol. Chem., 248: 4793 (1973).

Copyright (C) 1982 International Pediatric Research Foundation, Inc. $0031-3998 / 82 / 1611-0933 \$ 02.00 / 0$
38. Yoshioka, T., Sugiue, A., Shimada, T., and Utsumi, K.: Superoxide dismutase activity in the maternal and cord blood. Biol. Neonate, 36: 173 (1979).

39. Study performed in partial fulfillment of requirements for Ph.D. thesis.

40. Requests for reprints should be addressed to: Dr. Emmanuel Shapira, Head, Sections of Clinical and Biochemical Genetics, Department of Pediatrics, Tulane University School of Medicine, 1430 Tulane Avenue, New Orleans, Louisiana 70112 .

41. This research was supported by grants from the March of Dimes Birth Defects Foundation and the Edward G. Schlieder Educational Foundation.

42. Received for publication January $14,1982$.

43. Accepted for publication April 28. 1982

Printed in U.S.A. 